NASA/CR-1998-208675

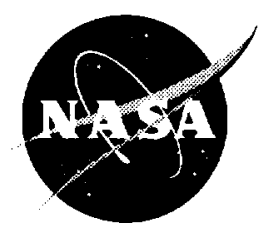

\title{
Long Term Degradation of Polymide Composites
}

Kaustubh A. Patekar and Hugh L. McManus

Massachusetts Institute of Technology, Cambridge, Massachusetts

Prepared for the

Eighth U.S.-Japan Conference on Composite Materials

sponsored by the Amercian Composite Society

Baltimore, Maryland, September 24-25, 1998

Prepared under Grant NAG3-2054

National Aeronautics and

Space Administration

Lewis Research Center 


\section{Acknowledgments}

This work was supervised by Dr. K.J. Bowles of the NASA Lewis Research Center and was carried out under Grant NAG3-2054, "Improved Mechanism-Based Life Prediction Models."

Trade names or manufacturers' names are used in this report for identification only. This usage does not constitute an official endorsement, either expressed or imp ied, by the National Aeronautics and Space Administration.

Available from

NASA Center for Aerospace Information 7121 Standard Drive

Hanover, MD 21076

Price Code: A03
National Technical Information Service 5285 Port Royal Road Springfield, VA 22100

Price Code: A03 


\title{
LONG TERM DEGRADATION OF POLYMIDE COMPOSITES
}

\author{
Kaustaubh A. Patekar and Hugh L. McManus \\ Massachusetts Institute of Technology \\ Cambridge, Massachusetts 02139
}

\begin{abstract}
The durability of polymer matrix composites exposed to harsh environments is a major concern. Surface degradation and damage are observed in polyimide composites used in air at $125-300^{\circ} \mathrm{C}$. It is believed that diffusion of oxygen into the material and oxidative chemical reactions are responsible. Previous work has characterized and modeled diffusion behavior, and thermogravimetric analyses (TGAs) have been carried out in nitrogen, air, and oxygen to provide quantitative information on thermal and oxidative reactions. However, the model developed using these data did not successfully extrapolate TGA data down to conditions seen in service. A test program that focuses on lower temperatures and makes use of isothermal tests was undertaken to achieve a better understanding of the degradation reactions under use conditions. A new, low-cost technique was developed to collect chemical degradation data for isothermal tests lasting over 200 hours in the temperature range $125-300^{\circ} \mathrm{C}$. Results indicate complex behavior not captured by the previous model, including the presence of weight-adding reactions. Weight gain reactions dominated in the $125-225^{\circ} \mathrm{C}$ temperature range, while weight loss reactions dominated beyond $225^{\circ} \mathrm{C}$. The data obtained from isothermal tests and earlier TGAs is used to develop an advanced model of the material behavior.
\end{abstract}

\section{INTRODUCTION}

Composite materials are widely used in applications where they are exposed to high temperatures, thermal cycling and air. The durability of composites under such exposure is not well understood. The design of composites for such applications can be significantly improved by modeling the various degradation phenomena in such materials [1]. This can be achieved through the development of a model which can incorporate known quantities such as laminate geometry, material properties, temperatures and chemical environment, and from these determine the material degradation state as a function of exposure time and position within the material [2]. A schematic of the desired coupled analysis which could provide this capacity is shown in Figure 1. Each module shown in the figure needs to be well understood in order to be able to predict composite behavior under environmental and thermal exposure. Efforts of several researchers have improved the understanding of these modules. In this research, we have focused on chemical degradation.

Kaustubh A. Patekar, Massachusetts Institute of Technology, Room 41-219, Cambridge, MA 02139

Hugh L. McManus, Massachusetts Institute of Technology, Room 3.3-311, Cambridge, MA 021.39

NASA/CR-1998-208675 


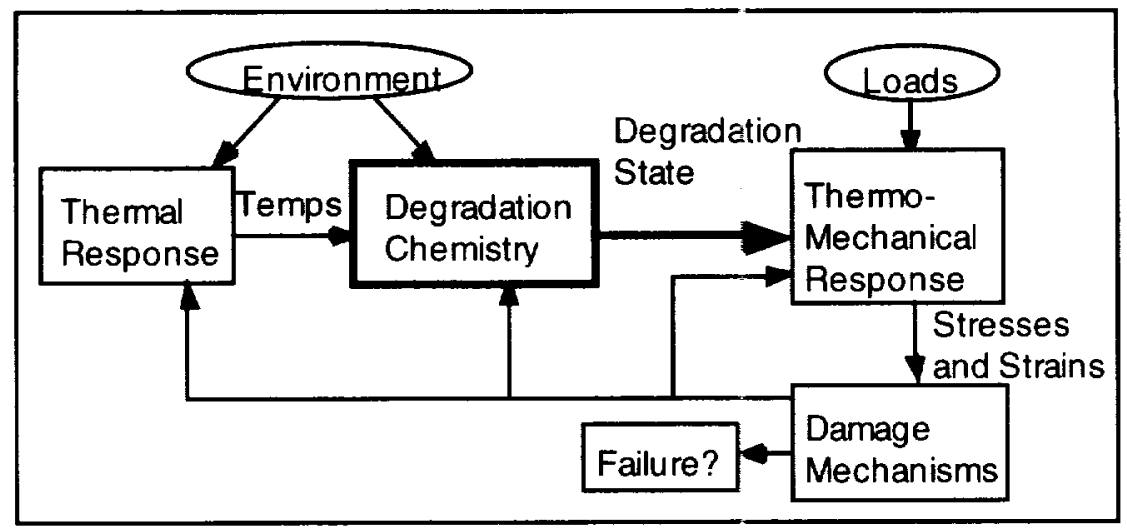

Figure 1. Comprehensive modeling flowchart

\section{PREVIOUS WORK}

It has been observed that macroscopic resin and composite specimens exposed to air at high temperatures develop a noticeable surface layer, and eventually damage such as crazing $[3,4]$. This is thought to be due to the combined effects of diffusion of oxygen into the material and chemical reaction [3]. This complicated multi-mechanism behavior makes interpretation of tests using macroscopic specimens difficult. Cunningham [1] separated diffusion and reaction effects by using finely ground powder specimens. This eliminates diffusion as a consideration, and allows work to be concentrated on the chemistry of degradation. Chemical degradation is also the focus of this work.

Work done by Cunningham [1] is reviewed here. TGA tests were carried out in nitrogen, air and oxygen for various heating rates. Powdered PMR-15 samples were heated from room temperature to $800^{\circ} \mathrm{C}$. Mass loss and mass loss rate data was obtained from these experiments. An Arrhenius reaction based model was used for explaining this data. Two thermal and one oxidative reaction were used. The reaction coefficients were obtained from the data using Kissinger's method. The model worked well for high lieating rates, but did not capture the behavior at lower heating rates. This model was also not a jle to explain the results of isothermal tests carried out in nitrogen, especially at lower temperatures $\left(<300^{\circ} \mathrm{C}\right)$.

\section{PROBLEM}

The focus of this research is to develop a model of the chemical degradation of a polyimide matrix material composite such that, given the histories of chemical environment and temperature, we can calculate quantitative metrics of chem cal degradation, as functions of time. 


\section{APPROACH}

The approach consists of experimental and analytical work. Experiments were conducted with the aim of improving the understanding of the chemical degradation under service conditions and building an advanced model. As previous models had failed to explain the behavior during long term isothermal exposure, long term isothermal tests were conducted at various temperatures, in air, using a newly designed, low cost test apparatus. The experimental data was then used to obtain the coefficients of an advanced chemical model.

\section{EXPERIMENTAL PROCEDURE}

Powdered specimens were obtained from plaques of neat PMR-15 resin. A small amount of this fine powder was placed in a thermocycling oven and aged for a duration of about 200 hours. The sample was placed in an aluminum pan and weighed periodically to measure the mass loss (or gain) due to the chemical degradation. One specimen was tested at each of the temperatures. Specimens were aged in air.

\section{MATERIAL PREPARATION}

All material was manufactured at the NASA Lewis Research Center using standard manufacturing procedures developed for the PMR polyimides. The details of these procedures may be found in [5]. After curing, all specimens were subjected to a 16 hour free-standing postcure in air at $316^{\circ} \mathrm{C}$. Two PMR- 15 neat resin plaques (both $102 \mathrm{~mm} \times 102 \mathrm{~mm}\left(4^{\prime \prime} \times 4 "\right)$ were used during this study. Specimens were taken from the neat resin plaques for use in the isothermal heating tests. Small strips were cut from the resin plaques and then powdered in a coffee grinder. A fine, light-brown powder was obtained. The powder was then sifted through a No. 40 sieve.

Tests conducted by Cunningham [1] had indicated that the particles obtained through the use of a No. 40 USA Standard Testing Sieve ( 425 micron grating) were sufficiently small to ensure that the effects of diffusion on the weight loss behavior in oxidative environments would be negligible. All powder produced in this manner was placed in small, unsealed glass jars and heated for 2 hours at $125^{\circ} \mathrm{C}$ to remove any residual moisture. The glass jars were immediately sealed after removal from the oven and the powder was stored like this until testing.

\section{PROCEDURE}

All powdered neat resin samples were aged in a thermal chamber. The chamber used electric resistance rods for heating and a fan for circulating air. The temperature of the chamber was controlled through the use of an Omega temperature controller. This microprocessor-based controller could be programmed to any user-defined thermal profile consisting of a series of linear segments. A single J-type thermocouple provided feedback to the controller.

A clean aluminum pan, spatula and pincers were used for each experiment. A custom rack was used for supporting the powdered specimen placed in an aluminum pan. These were cleaned with water and then with methanol and dried for 15 minutes in a clean-air hood. A new pan was used for each experiment. An AE 100 Mettler balance with a least count of $0.1 \mathrm{mg}$ was used for 
weighing the sample-pan. The clean pan was weighed first, and then a sample of about $600 \mathrm{mg}$ of the prepared powder was placed in it. The weighing balance was recalibrated and its leveling checked, before each experiment. The sample was then ht ated to $125^{\circ} \mathrm{C}$ and held for two hours. The pan was removed from the chamber and weighed at the end of these two hours. The sample mass obtained from this measurement was utilized as the starting sample mass during all further calculations. The chamber was then heated to the test temperature and then held there for a duration in excess of 200 hours. The test cycle temperature ramp is shown in Figure 2, where RT stands for room temperature.

The sample pan was removed periodically from the thermocycling oven for weight measurements. The pan was then weighed using the sensitive balance and then put back into the thermocycling chamber. This procedure lasted less than a minute. The test chamber temperature dropped because the door was opened twice during each measurement. However, the test temperature was restored in less than five minutes due to the large thermal mass of the chamber. As tests were conducted for more than 200 hours, and readings taken with an average gap of six hours (360 minutes) this temperature drop was not considered in further calculations and the sample was assumed to be at a steady temperature throughout the duration of the test.

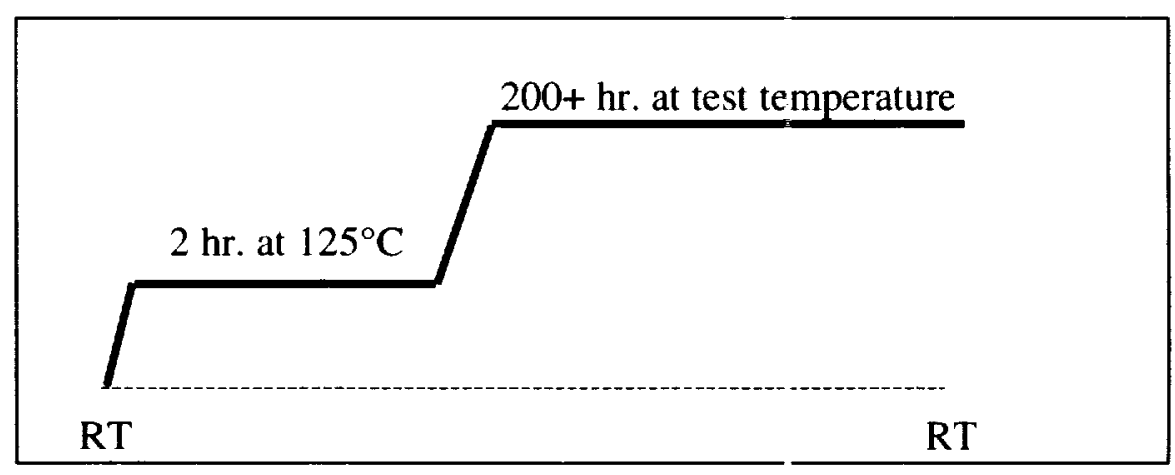

Figure 2. Long term isothermal heating cycle

A test was conducted in which a pan with powdered resin sample was held at $125^{\circ} \mathrm{C}$ for over 200 hours. No reactions are known to occur at this temperature and this experiment was conducted to study the extent of possible scatter and any other sources of error. The weighing balance takes a few seconds to give a steady reading. This reading can be affected by any potential moisture absorption during this period. The readings showed a variation of $+1.0 \mathrm{mg}$ to $-1.1 \mathrm{mg}$. Lack of any trend in this data showed that the sample was not being blown away by the circulation fan and that error due to sources such as moisture absorption was small $(0.2 \%)$.

\section{ANALYSIS}

A basic Arrhenius chemical reaction model is used to describe the oxidative reactions. Mass loss (or gain) is used as a degradation metric. Three differe it Arrhenius reactions were considered. Two of these reactions lead to mass loss whereas one reaction leads to mass gain. The analysis is implemented through the use of an explicit time-step finite difference computer code. Degradation state of the material is calculated as a function of exposure time and temperature. The analysis was used to reduce mass loss data from powdered specimens to 'a set of chemical reaction constants. 
In the notation of Cunningham [1], the reaction is considered to take place inside an infinitesimal control volume containing a mass $m_{v}$ of matrix material. The fibers are assumed to be stable. The matrix material is assumed to consist of different components that are available for various reactions. A mass $m_{i}$ is defined as the mass that would be lost (or gained) due to the completion of a set of reactions involving component $i$. A mass fraction $y_{i}$ is defined as the ratio between the mass of component $i$ and the overall mass

$$
y_{i}=\frac{m_{i}}{m_{i}}
$$

A conversion metric $\alpha_{i}$ is used to keep track of the degradation of mass fraction $y_{i}$. When $\alpha_{i}$ is equal to zero, no degradation has taken place; when $\alpha_{i}$ is equal to one, the mass fraction is entirely lost (or gained). The rate at which mass is lost (or gained) from the control volume due to degradation of component $i$ is

$$
\frac{\partial m_{i}}{\partial t}=-m_{0} y_{i} \frac{\partial \alpha_{i}}{\partial t}
$$

The total mass lost from component $i$ is

$$
\Delta m_{i}=\int_{0}^{t} \frac{\partial m_{i}}{\partial t}
$$

Finally, the mass lost from the control volume is

$$
\Delta m=\sum_{\text {all }} \Delta m_{i}
$$

Arrhenius reaction kinetics are assumed for the chemical reactions acting on the different mass fractions. Reaction rates for each material component $i$ are related to the conversion metric, $\alpha_{i}$, and to the absolute temperature, $T$, by different and independent functions. A complete kinetic description of a chemical reaction requires the characterization of both [6] the rate (temperature-dependence) function, and the conversion-dependence function. The rate functions is described as

$$
F(T)=k_{i} \exp \left(\frac{-E_{i}}{R T}\right)
$$

where $k_{i}$ is the reaction rate constant, $E_{i}$ is the activation energy that represents the energy barrier which must be surmounted during transformation of reactants into products, and $R$ is the real gas constant. The conversion-dependence function is expressed as $\left(1-\alpha_{i}\right)^{n_{i}}$ assuming $n_{i}$ thorder kinetics, where $n_{i}$ is the order of the reaction. The total reaction rate is then described by

$$
\frac{\partial \alpha_{i}}{\partial t}=k_{i}\left(1-\alpha_{i}\right)^{n_{i}} \exp \left(\frac{-E_{i}}{R T}\right)
$$


This is the basic form of the equation used in the model. Further details of the modeling are found in reference [1].

\section{FIT PROCEDURE}

A three reaction model was used to correlate the analytical model with the experimental data. All three reactions were assumed to be oxidative, as all the test were conducted in air. Observations indicated two mass loss and one mass gain reaction would be required to model the data. Some of these reactions appeared to reach saturation (no further mass loss/gain observed). The mass fractions $y$, for the reactions which show saturation behavior were estimated from observed data. One of the reactions did not show saturation. The mass fraction on which this reaction acts was estimated on the basis of curve-fitting and observations recorded in [1]. The reaction coefficients for this model $\left(k_{i}, n_{i}\right.$ and $\left.E_{i}\right)$ were obtained by using a least squares fit to different data sets. A standard optimization tool available in MATLAB (version 5.2) was used for this purpose. This tool makes use of the Levenberg-Marquardt method.

\section{EXPERIMENTAL RESULTS}

The experimental results for long term isothermal tests in air are shown in Figures 3 and 4. The normalized mass loss is plotted against the time in hours. The original mass was obtained from the weighing of the sample after heating it for 2 hou rs at $125^{\circ} \mathrm{C}$. The mass loss observed was normalized with respect to original sample mass for exch experiment. No mass loss or gain trend is observed at $125^{\circ} \mathrm{C}$.

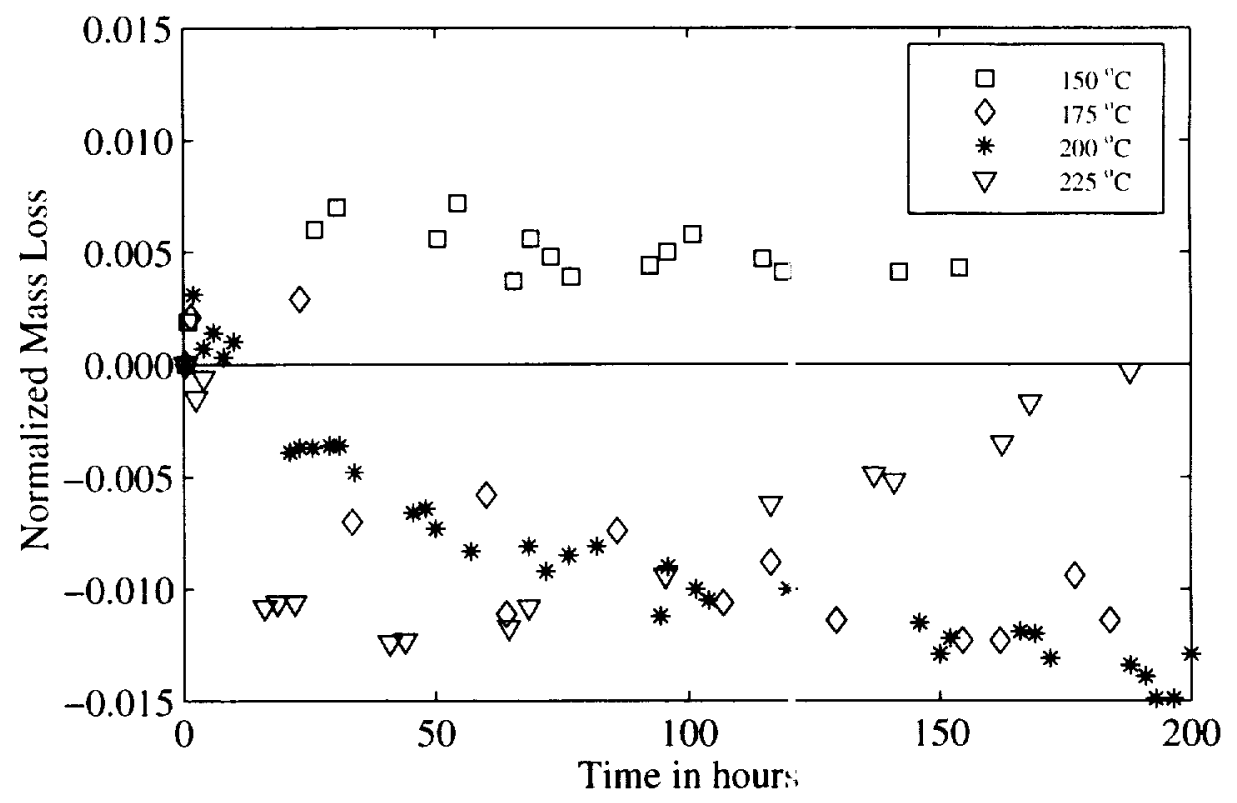

Figure 3. Long term isothermal test data for temperatures from $125-225^{\circ} \mathrm{C}$ 
Mass loss is observed at $150^{\circ} \mathrm{C}$. Mass gain is observed at $175^{\circ} \mathrm{C}$ and $200^{\circ} \mathrm{C}$. The total mass gain seems to saturate beyond a duration of 200 hours. At $225^{\circ} \mathrm{C}$, a transition from mass gain to mass loss can be seen. The mass loss behavior dominates for all higher temperatures, as shown in Figure 4.

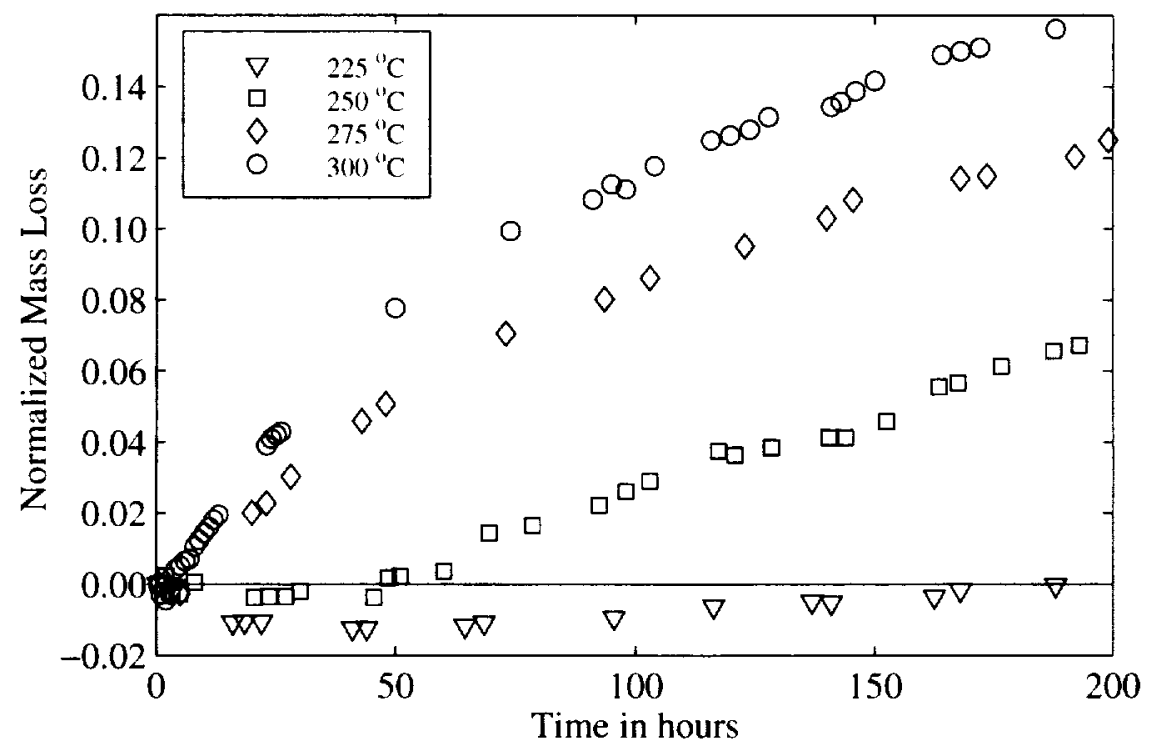

Figure 4. Long term isothermal test data for temperatures from $225-300^{\circ} \mathrm{C}$

\section{CORRELATION}

The coefficients for the three reactions in the model and the mass fractions on which they act were obtained from the experimental observations. We assumed a small mass loss reaction (see $150^{\circ} \mathrm{C}$ ), a small mass gain reaction (see $175-200^{\circ} \mathrm{C}$ ), and a mass loss reaction that affected a large mass fraction. The saturation behavior seen in $150-200^{\circ} \mathrm{C}$ test was utilized for obtaining the mass fractions for the two small mass change reactions. The large mass fraction for the third reaction was estimated using a numerical search.

The three coefficients for each reaction consisting of rate constant $K_{i}$, reaction order $n_{i}$, and activation energy $E_{i}$ were estimated using a optimization procedure in two steps. In the intermediate step, each reaction was modeled using $C_{i}$ and $n_{i}$, where

$$
C_{i}=k_{i} \exp \left(\frac{-E_{i}}{R T}\right)
$$

A least squares fit was obtained for each data set. The reaction order $n_{i}$ values obtained from each data set for three different reactions were found to be in a narrow range. In the next step, each reaction was quantified using all the three coefficients and with constraints placed on the reaction order variables. The least squares error from each data set was normalized by the mean mass loss (or gain) value observed. The sum of these error values was minimized using a constrained optimization approach. The coefficients obtained are listed in Table 1. The curves generated using these reaction coefficients are plotted along with the data in Figures 5, 6 and 7. 
Table I - Results of Optimization for Three Reaction Model

\begin{tabular}{|ll|ccc|}
\hline & & 1 & 2 & 3 \\
\hline Mass fraction & $v_{i}$ & 0.008 & -0.026 & 0.35 \\
Rate constant & $k_{i}$ & $12.8 \times 10^{*}$ & $8.67 \times 10^{8}$ & $9.65 \times 10^{8}$ \\
Activation energy & $E_{i}(\mathrm{KJ} / \mathrm{mol})$ & 109 & 124 & 155 \\
Reaction order & $n_{i}$ & 1.0 & 2.1 & 3.6 \\
\hline
\end{tabular}

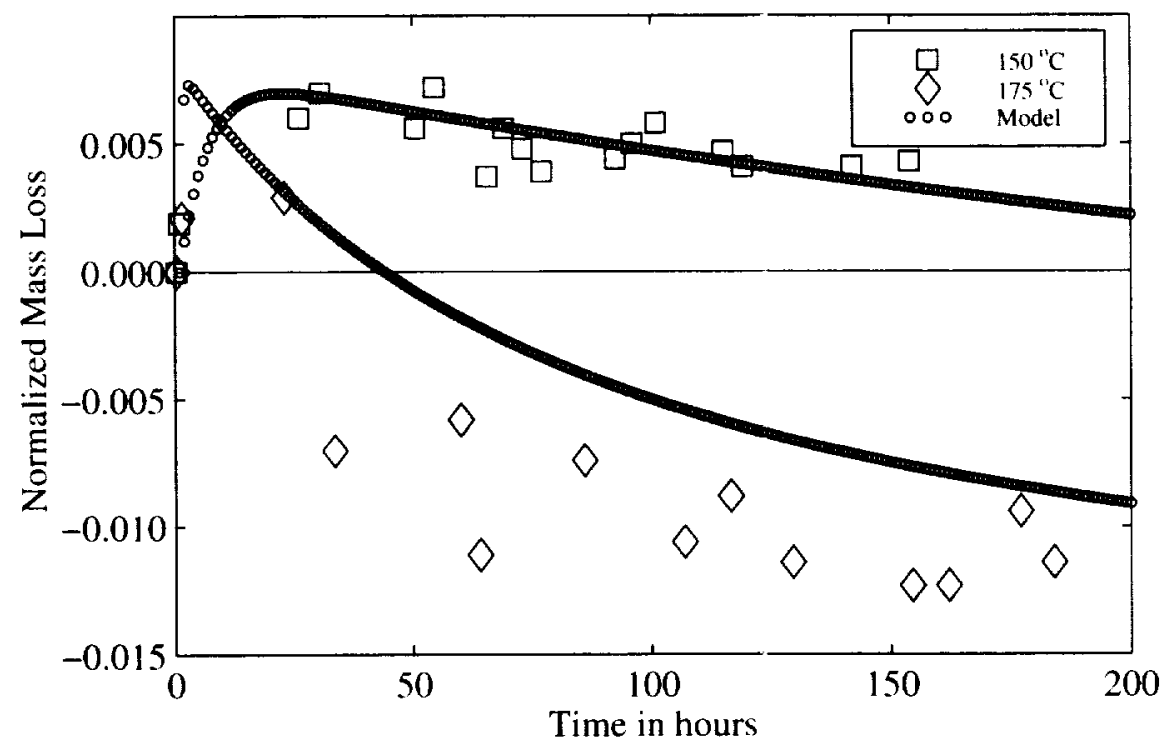

Figure. 5 Comparison of model and data for $150-175^{\circ} \mathrm{C}$

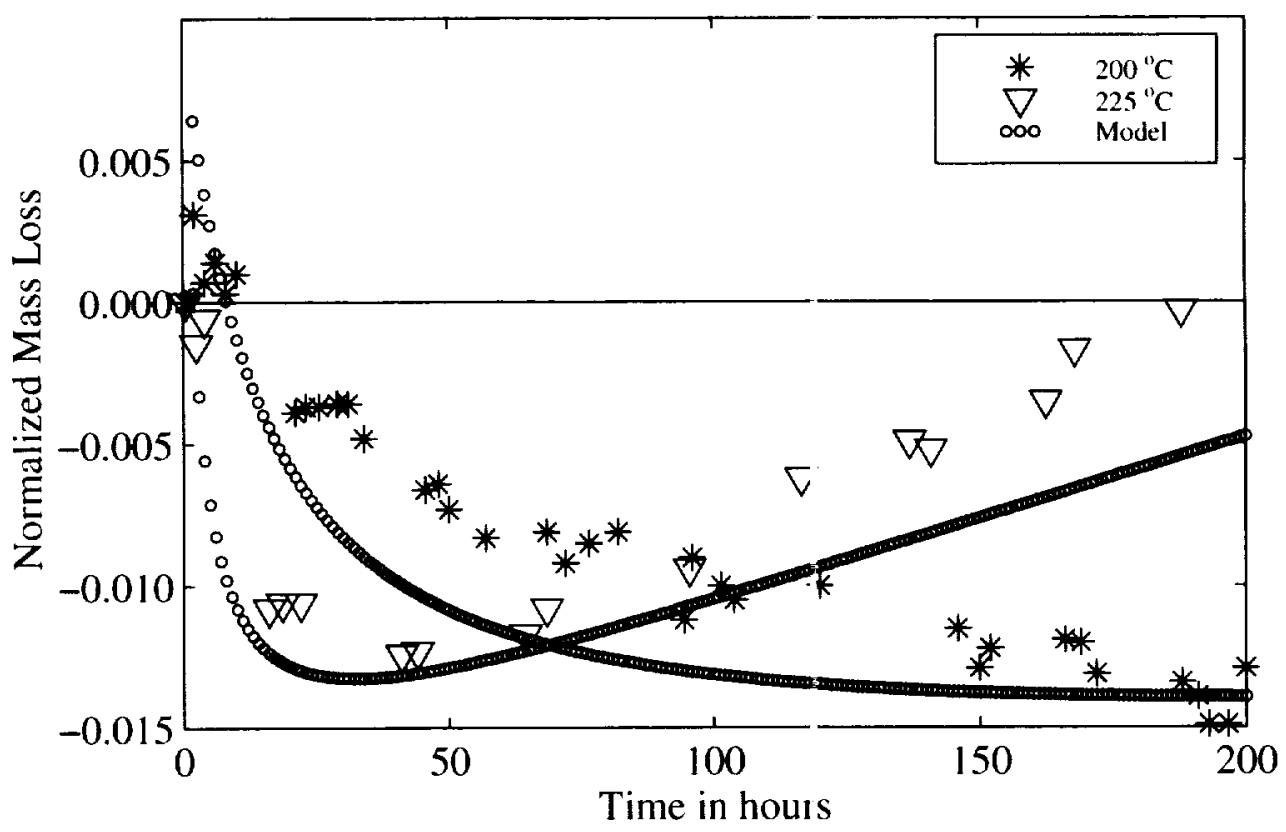

Figure. 6 Comparison of model and data for $200-225^{\circ} \mathrm{C}$ 


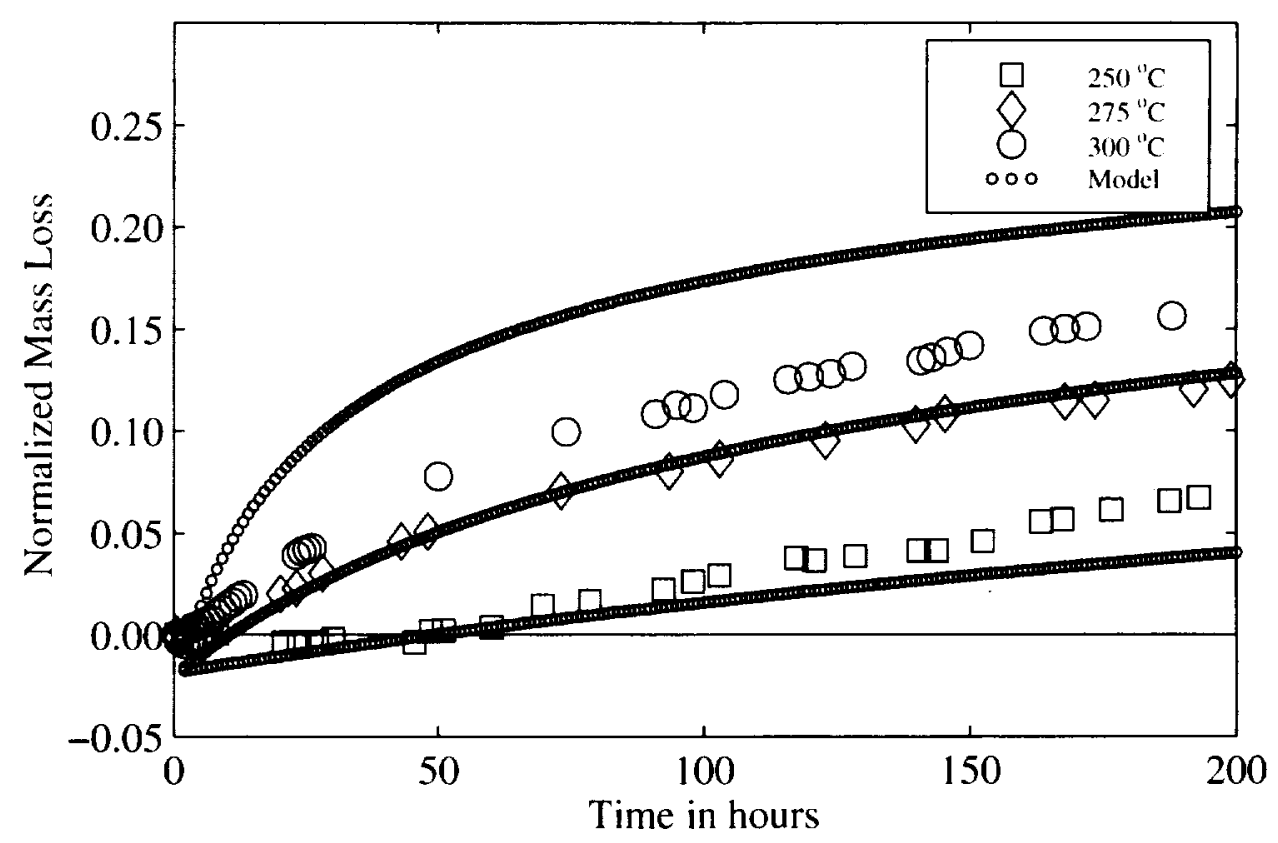

Figure. 7 Comparison of model and data for $250-300^{\circ} \mathrm{C}$

\section{CONCLUSIONS}

The newly developed test method is a useful way of precisely measuring the mass loss/gain behavior and is cost-effective for long duration isothermal tests. The three reaction model is able to capture the mass loss and gain trends reasonably well. The mass gain behavior, not captured in previous models, is adequately quantified in this new model. The model does not succeed in capturing the behavior at $300^{\circ} \mathrm{C}$. This is thought to be because of a transition from low temperature to high temperature behavior. Higher temperature behavior is captured by the model of Cunningham [1]. The new model used in conjunction with the previous model, captures material degradation behavior at all temperatures of interest.

\section{REFERENCES}

1. Cunningham, R. A. 1997. "High Temperature Degradation Mechanisms in Polymer Matrix Composites," S.M. Thesis, Massachusetts Institute of Technology, Cambridge, MA.

2. McManus, H. L. and C. C. Chamis. 1996. "Stress and Damage in Polymer Matrix Composite Materials Due to Material Degradation at High Temperatures," NASA Technical Memorandum 4682.

3. Bowles, K. J., D. Jayne, and T .A. Leonhardt. 1993. "Isothermal Aging Effects on PMR-15 Resin", SAMPE Quarterly. Vol. 24, No. 2, pp. 3-9.

4. Martin, R. H., E. J. Siochi, and T. S. Gates. 1992. "Isothermal Aging of IM7/8320 and IM7/5260". American Society for Composites 7th Technical Conference on Composite Materials, University Park, PA, pp. $207-217$.

5. Boyd, J. D. and G. E. C. Chang. 1993. "Bismaleimide Composites for Advanced High-Temperature Applications," 38th International SAMPE Symposium, Covina, CA, pp. 357-365.

6. Meador, M. A., P. J. Cavano, and D. C. Malarik. 1990. "High Temperature Polymer Matrix Composites for Extreme Environments", Sixth Anmual ASM/ESD Advanced Composites Conference, Detroit, MI, pp. 529-539. 
Public reporting burden for this collection of information is estimated to average 1 hour per response, includir $g$ the time for reviewing instructions. searching existing data sources. gathering and maintaining the data needed, and completing and reviewing the collection of information. Sent: comments regarding this burden estimate or any other aspect of this collection of information, including suggestions for reducing this burden, to Washington Headquarters Service $i$, Directorate for Information Operations and Reports. 1215 Jefferson Davis Highway. Suite 1204. Arlington. VA 22202-4302. and to the Office of Management and Budget. Paper vork Reduction Project (0704-0188). Washington, DC 20503.

\begin{tabular}{l|l|l|} 
1. AGENCY USE ONLY (Leave blank) & 2. REPORT DATE & 3. AEPORT TYPE AND DATES COVERED
\end{tabular}

\begin{tabular}{|l|l|l|}
\hline 1. & December 1998 & Final Contractor Report \\
\hline
\end{tabular}

\section{TITLE AND SUBTITLE}

Long Term Degradation of Polymide Composites

\section{FUNDING NUMBERS}

WU-523-21-1.3-00

NAG3-2054

\section{AUTHOR(S)}

Kaustubh A. Patekar and Hugh L. McManus

7. PERFORMING ORGANIZATION NAME(S) AND ADDRESS(ES)

Massachusetts Institute of Technology

77 Massachusetts Ave.

Cambridge, Massachusetts 021.39

8. PERFORMING ORGANIZATION

REPORT NUMBER

E-11405

9. SPONSORING/MONITORING AGENCY NAME(S) AND ADDRESS(ES)

National Aeronautics and Space Administration

Lewis Research Center

Cleveland, Ohio 44135-3191

10. SPONSORING/MONITORING AGENCY REPORT NUMBER

NASA CR-1998-208675

\section{SUPPLEMENTARY NOTES}

Prepared for the Eighth U.S.-Japan Conference on Composite Material; sponsored by the American Composite Society, Baltimore, Maryland, September 24-25, 1998. Project Manager, Kenneth J. Bowles, Materials Division, NASA Lewis Research Center, organization code 5150, (216) 433-3197.

12a. DISTRIBUTIONAVAILABILITY STATEMENT 12b. DISTRIBUTION CODE

Unclassified - Unlimited

Subject Category: 24

Distribution: Norstandard

This publication is available from the NASA Center for AeroSpace Information. (3111) 621-0390.

13. ABSTRACT (Maximum 200 words)

The durability of polymer matrix composites exposed to harsh environınents is a major concern. Surface degradation and damage are observed in polyimide composites used in air at $125-300^{\circ} \mathrm{C}$. It is believed that diffusion of oxygen into the material and oxidative chemical reactions are responsible. Previous wo:k has characterized and modeled diffusion hehavior, and thermogravimetric analyses (TGAs) have been carried otit in nitrogen, air, and oxygen to provide quantitative information on thermal and oxidative reactions. However. the mod 1 developed using these data did not successfully extrapolate TGA data down to conditions seen in service. A test progra $n$ that focuses on lower temperatures and makes use of isothermal tests was undertaken to achieve a better understanding of the degradation reactions under use conditions. A new, low-cost technique was developed to collect chemical degradation data for isothermal tests lasting over 200 hours in the temperature range $125-300^{\circ} \mathrm{C}$. Results indicate complex behavior not captured by the previous model, including the presence of weight-adding reactions. Weight gain reactions dominated $n$ the $125-225^{\circ} \mathrm{C}$ temperature range, while weight loss reactions dominated beyond $225^{\circ} \mathrm{C}$. The data obtained from isothormal tests and earlier TGAs is used to develop an advanced model of the material hehavior.

14. SUBJECT TERMS

Polymers; Polymide; Composites; Durability; Modeling; Thermal stability

17. SECURITY CLASSIFICATION OF REPORT

Unclassified
18. SECURITY CLASSIFICATION OF THIS PAGE

Unclassified 19. SECURI IY CLASSIFICATION
OF ABS TRACT
L nclassified
15. NUMBER OF PAGES

$$
15
$$

16. PRICE CODE $\mathrm{AO} 3$

\section{LIMITATION OF ABSTRACT}

